\title{
Detection and Determination of Organic Impurities in Food Coal-Tar Dyes by High Performance Liquid Chromatograpy
}

\author{
(Received August 21, 1982)
}

\author{
Yasuhide TonogaI, Yoshio ITo and Masahiro IwAIDA \\ (National Institute of Hygienic Sciences, Osaka Branch: 1-1-43, Hoenzaka, \\ Higashi-ku, Osaka, Japan)
}

\begin{abstract}
A systematic detection and determination method for organic impurities in 7 kinds of food coal-tar dyes (Tartrazine, Sunset Yellow FCF, Amaranth, New Coccine, Fast Green FCF, Brilliant Blue FCF and Indigo Carmine) was developed by the use of high performance liquid chromatography (HPLC) under the following operating conditions: Zipax SAX (strong anion exchange type resin) column; gradient elution system of $0.01 M$ sodium borate solution and $0.1 \mathrm{M}$ sodium perchlorate solution; UV detection at $254 \mathrm{~nm}$ as well as at the maximal absorbance wavelength of each dye. In order to try to introduce HPLC as a purity test in the Japanese Standards of Food Additives (JSFA), a regulation system for organic matter impurities is proposed based on total contents of starting material residues and uncombined intermediates expressed as the amount of sulphanilic acid, while total contents of subsidiary dyes were expressed as the amount of original dyes. By the use of the proposed method, a survey was carried out on 105 samples of coal-tar dyes that had passed the government product examination during 1978-1980.
\end{abstract}

Key words: high performance liquid chromatography; food coal-tar dye; material; intermediate of organic synthesis; subsidiary dye; sulphanilic acid

\section{Introduction}

The current coloring matter tests of the Japanese Standards of Food Additives $(\text { JSFA })^{1)}$ cover such purity tests as assay of dye content, other coloring matters, water. insoluble substance, chloride and sulfate contents, heavy metals, arsenic and so on. Residual starting materials as well as colorless uncombined intermediates, however, are not regulated. Other coloring matters are tested by examining the presence of subsidiary spots on a paper chromatogram using $0.002 \mathrm{ml}$ of $0.1 \%$ solution. Accordingly, it is impossible to detect small amounts of subsidiary dyes, the detection limit probably being about $3 \%$ of the original food coal-tar dyes. In order to assure the safety of food coal-tar dyes, stricter tests should be developed and adopted in the next version of JSFA.

Up to now, column chromatographic methods have been developed for the inspection of organic impurities ${ }^{2), 3)}$; these methods, however, require rather complicated and timeconsuming procedures, and, moreover, they cannot separate the impurities distinctly from each other. Recently, HPLC has given promising results in the determination of coaltar dyes ${ }^{4), 5)}$ as well as their organic impurities ${ }^{6) \sim 8)}$.

In this investigation, we attempted to apply HPLC as a purity test to determine residual starting materials and reaction intermediates of the organic synthesis of food coaltar dyes, and we succeeded in establishing a common inspection method for 7 kinds of food coal-tar dyes (four azo dyes, two triphenylmethane dyes and one indigoid dye). By the use of the established method, a survey was carried out on 105 samples which had been produced during 1978-1980. 


\section{Experimentals}

\section{Reagents}

Reference standards of the National Institute of Hygienic Sciences (Amaranth, New Coccine, Acid Red, Erythrosine, Rose Bengal, Phloxine, Tartrazine, Sunset Yellow FCF, Fast Green FCF, Brilliant Blue FCF and Indigo Carmine) were used. $p$-Nitrophenol and sulfanilic acid were guaranteed grade products from Tokyo Chemical Industry Co., Ltd. Isatin-5-sulfonic acid, indigo-5, $7^{\prime}$-disulfonic acid and indigo-5-sulfonic acid were guaranteed grade products from Aldrich Chemical Company, Inc. All the other reagents used were of analytical grade.

\section{Apparatus}

A Shimadzu LC-3A high performance liquid chromatograph was used with a GRE-2B gradient elution accessory, SPD-1 multi-wavelength detector (used at $254 \mathrm{~nm}$ and at the maximal absorbance of each dye) and C-R1A computing integrator chromatopak. It was

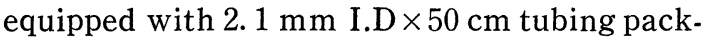
ed with DuPont "Zipax SAX" (strong anion exchange type). Operating conditions were as follows. Primary eluant $(P), 0.01 M$ sodium borate solution; secondary eluant $(S)$, $0.1 M$ sodium perchlorate solution in $0.01 M$ sodium borate solution; gradient profile, $P$ $5 \mathrm{~min}, 0-35 \% \mathrm{~S}$ in $(P+S) 5 \% / \mathrm{min}, 35-100 \% \mathrm{~S}$ in $(P+S) 10 \% / \mathrm{min}$, and $S 5 \mathrm{~min}$. Flow rate was $1 \mathrm{ml} / \mathrm{min}$. Before beginning the next analysis, $P$ solution was passed for $10 \mathrm{~min}$. 3. Samples

The same kinds of dyes as the reference standards were used; the samples had passed the regular product examination. A $1 \mathrm{~g}$ portion of each sample was dissolved in $50 \mathrm{ml}$ of water, $10 \mathrm{ml}$ of $0.1 \% p$-nitrophenol solution was added as an internal standard, and the whole was made up to $100 \mathrm{ml}$ with water.

\section{Preparation of calibration curves}

Aliquots of $0,5,10,15,20$ and $25 \mathrm{ml}$ of $0.1 \%$ sulfanilic acid standard solution and $0.1 \%$ dye solution of reference standards were taken into separate flasks, then $10 \mathrm{ml}$ of $0.1 \%$ $p$-nitrophenol solution was added as an internal standard, and each mixture was made up to $100 \mathrm{ml}$ with water.

Five microliters of each solution was injected into the HPLC machine and ratios of peak areas of uncombined intermediates or other coloring matters to that of the internal standard were plotted against the amount of uncombined intermediates or other coloring matters.

\section{Estimation of organic impurities}

Quantities of subsidiary coloring matters $B$ are measured at the maximal absorbance wavelength of the dye (excluding the main peak), while the sum of residual starting materials and colorless uncombined intermediates corresponds to $A-B$, where $A$ is

Table 1. Retention Times of Internal Standard Substances and Starting Materials of Dyes by HPLC

\begin{tabular}{lclc}
\hline \multicolumn{1}{c}{ Internal standard } & $\begin{array}{c}\text { Retention time } \\
(\mathrm{min})\end{array}$ & Starting material & $\begin{array}{c}\text { Retention } \\
(\mathrm{min})\end{array}$ \\
\hline$p$-Hydroxybenzenesulfonic acid & 2.0 & Isatin & 1.2 \\
$p$-Hydroxybenzoic acid & 2.0 & Sulfanilic acid & 2.0 \\
-Aminobenzoic acid & 2.0 & Water (solvent) & 8.8 \\
Anthranilic acid & 2.0 & Isatin-5-sulfonic acid & 9.3 \\
Resorcinol & 2.0 & Naphthionic acid & 9.4 \\
Phthalic acid & 2.0 & Schäffer acid & 10.0 \\
$p$-Nitroaniline* & 3.9 & Pyrazolone derivative & 10.2 \\
$p$-Nitro-o-toluidine* & 5.1 & Croceic acid & 10.6 \\
$p$-Nitrophenol & 9.2 & R acid & 12.0 \\
$\alpha$-Naphthalenesulfonic acid & 11.0 & G acid & 12.5 \\
\hline
\end{tabular}

* broad peak

1) 1-(4-sulfophenyl)-3-ethylcarboxy-5-hydroxypyrazolone

2) 2-naphthol-3, 6-disulfonic acid

3) 2-naphthol-6, 8-disulfonic acid 


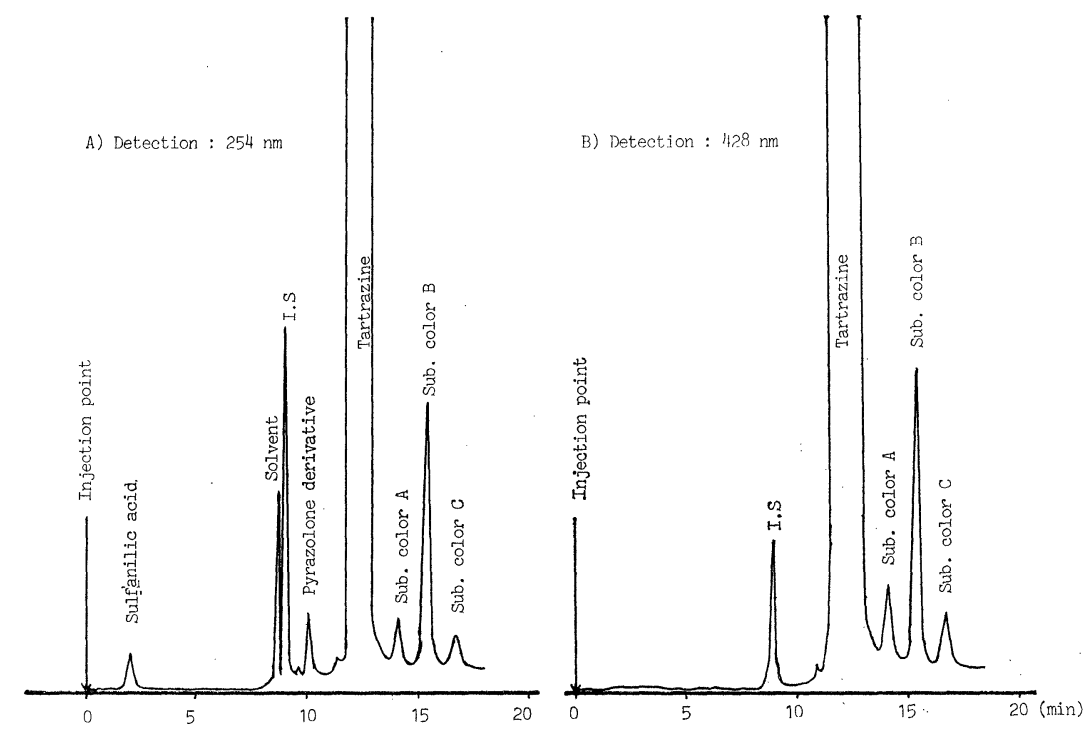

Fig. 1a. Elution patterns of Tartrazine on HPLC with detection at 254 and $428 \mathrm{~nm}$ (428 $\mathrm{nm}$ is the maximal absorbance wavelength of Tartrazine)

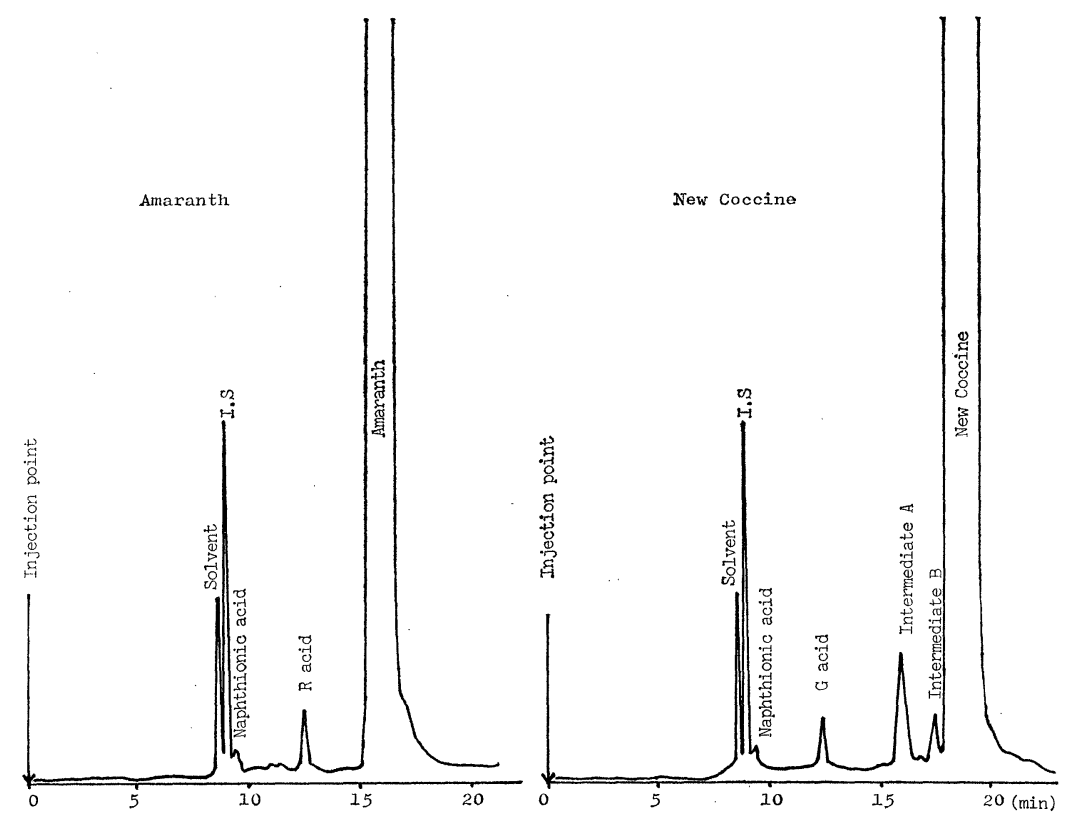

Fig. 1b. Elution patterns of Amaranth and New Coccine on HPLC Detection: $254 \mathrm{~nm}$ 


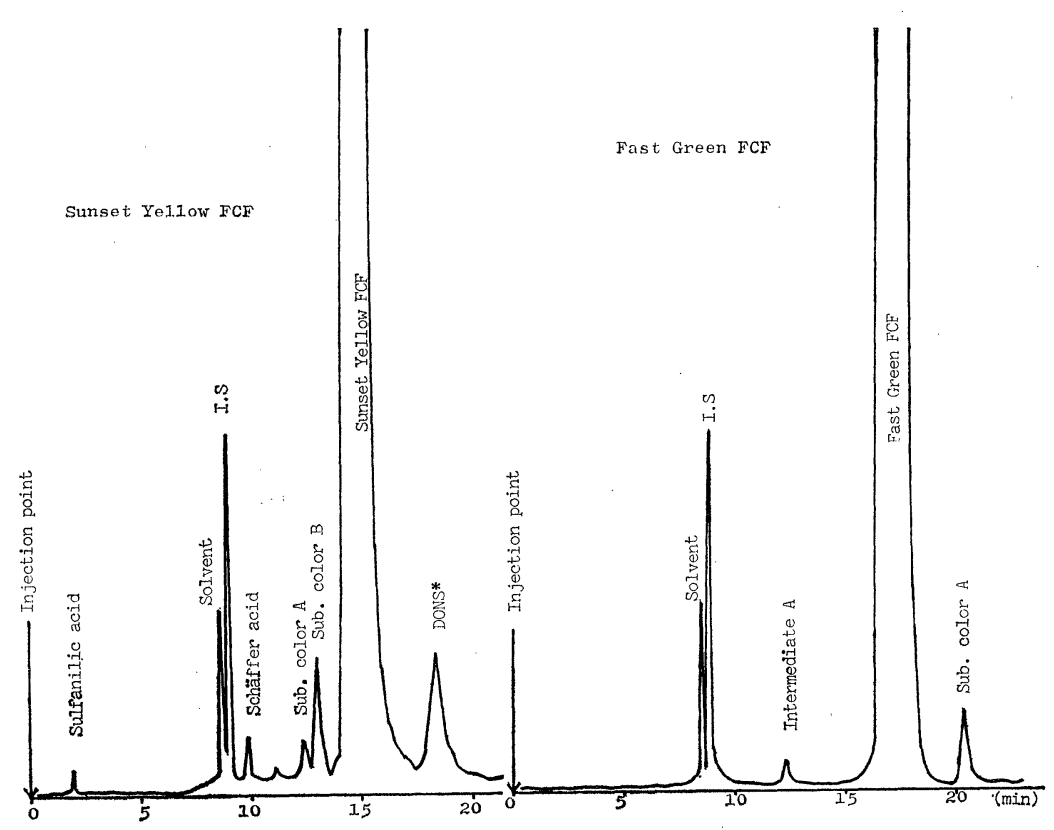

Fig. 1c. Elution patterns of Sunset Yellow FCF and Fast Green FCF on HPLC * 6, 6'-oxybis(2-naphthalenesulfonic acid)

Detection: $254 \mathrm{~nm}$

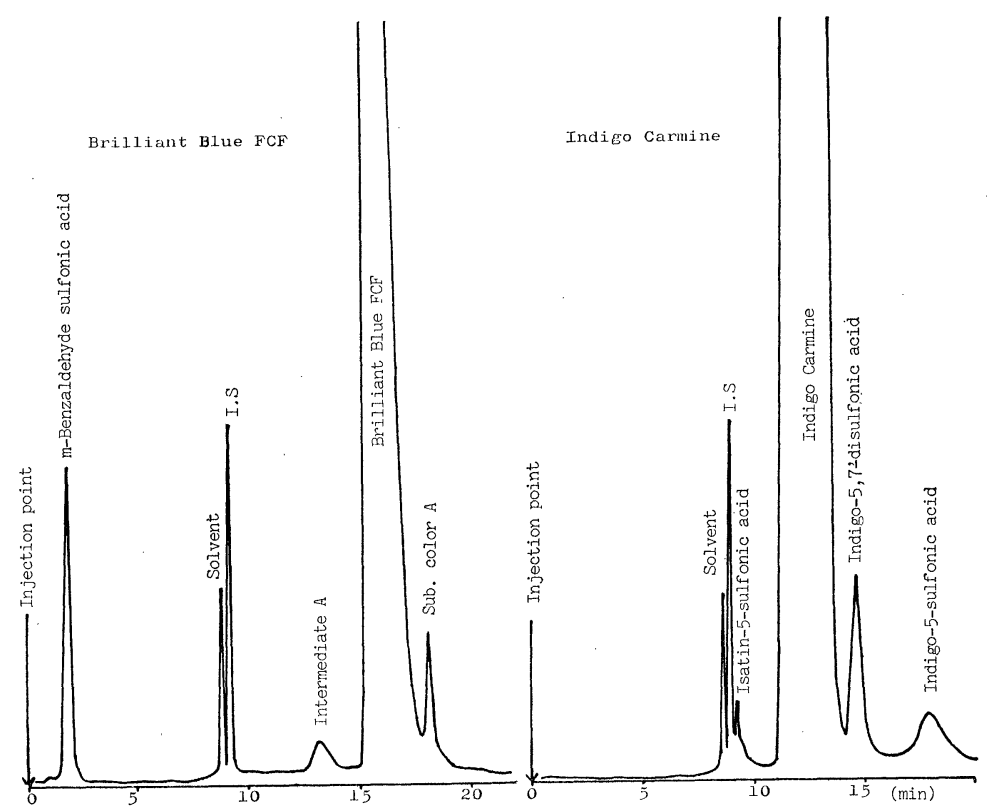

Fig. 1d. Elution patterns of Brilliant Blue FCF and Indigo Carmine on HPLC Detection: $254 \mathrm{~nm}$ 
the total peak area detected at $254 \mathrm{~nm}$ (excluding the main peak). The latter is expressed as sulfanilic acid, one of the important starting materials in azo dye synthesis, while the former is expressed as amount of each main dye.

In the case of Tartrazine, a sample solution was measured at the wavelength of $254 \mathrm{~nm}$ $(A)$, and then the same solution was measured at $428 \mathrm{~nm}$, the maximal absorbance wavelength of Tartrazine $(B)$ under the same conditions of HPLC. Total amounts of sulfanilic acid and pyrazolone derivative (colorless) were expressed as sulfanilic acid $(A-B)$, while subsidiary color $A, B$ and $C$ (with color) were expressed as amount of Tartrazine $(B)$, as shown in Fig. 1a.

\section{Results and Discussion}

1. Establishment of analytical conditions of HPLC

A combination of strong anion exchange type column and sodium borate-sodium perchlorate solution was appropriate for the anal- ysis of azo dyes, triphenylmethane dyes and Indigo Carmine, though Erythrosine, Phloxine, Rose Bengal and Acid Red (xanthene dyes) were not sufficiently eluted under these conditions.

When only $P$ eluant was run, a broad tailing peak of the main dye was obtained with relatively large retention time, but more compact chromatograms were obtained with the aid of the gradient elution system with mixtures of $P$ and $S$.

2. Adoption of a suitable internal standard

A survey was carried out in order to select a suitable internal standard for HPLC. The $\mathrm{t}_{R}$ values of internal standard substances and starting materials are summarized in Table 1.

Since the $\mathrm{t}_{R}$ of the internal standard must not overlap with those of other products, but should be similar, $p$-nitrophenol was finally chosen since it gives a sharp peak and has a moderate $t_{R}$ of $9.2 \mathrm{~min}$, being well separated from any peak of starting material or intermediate. Its final concentration in the sample solution was adjusted to $1.0 \%$.

Table 2. Detection and Determination of Organic Impurities in Food Coal-tar Dyes by HPLC

\begin{tabular}{|c|c|c|c|}
\hline Food coal-tar dye & Organic impurity & $\underset{(\min )}{\text { Retention time }}$ & $\begin{array}{c}\text { Content } \\
(\%)\end{array}$ \\
\hline \multirow[t]{3}{*}{ Tartrazine } & Sulfanilic acid & 2.0 & 0.28 \\
\hline & Pyrazolone derivative & 10.2 & 0.13 \\
\hline & Sub. color A, B, C & $14.2,15.5,19.8$ & - \\
\hline \multirow[t]{4}{*}{ Sunset Yellow FCF } & Sulfanilic acid & 2.0 & 0.04 \\
\hline & Schäffer acid & 10.0 & 0.07 \\
\hline & Sub. color A, B & $12.4,13.0$ & - \\
\hline & $\mathrm{DONS}^{1)}$ & 18.4 & 一 \\
\hline \multirow[t]{2}{*}{ Amaranth } & Naphthionic acid & 9.4 & 0.05 \\
\hline & $\mathrm{R}$ acid & 12.0 & 0.17 \\
\hline \multirow[t]{3}{*}{ New Coccine } & Naphthionic acid & 9.4 & 0.05 \\
\hline & $\mathrm{G}$ acid & 12.5 & 0.10 \\
\hline & Intermediate $\mathrm{A}, \mathrm{B}$ & $15.8,17.4$ & - \\
\hline \multirow[t]{2}{*}{ Fast Green FCF } & Intermediate $\mathrm{A}$ & 12.4 & - \\
\hline & Sub. color A & 20.5 & - \\
\hline \multirow[t]{3}{*}{ Brilliant Blue FCF } & $o$-Benzaldehydesulfonic acid & 1.8 & 0.41 \\
\hline & Intermediate $\mathrm{A}$ & 13.0 & - \\
\hline & Sub. color A & 18.4 & - \\
\hline \multirow[t]{3}{*}{ Indigo Carmine } & Isatin-5-sulfonic acid & 9.3 & 0.56 \\
\hline & Indigo-5, $7^{\prime}$-disulfonic acid & 14.6 & 0.78 \\
\hline & Indigo-5-sulfonic acid & 18.0 & 0.86 \\
\hline
\end{tabular}

\footnotetext{
1) 6,6'-oxybis(2-naphthalenesulfonic acid)
} 
Table 3. Organic Impurities in Various Food Coal-tar Dyes as determined by HPLC

\begin{tabular}{|c|c|c|c|c|c|c|c|c|c|c|c|}
\hline No. & $\begin{array}{c}\text { Food coal-tar } \\
\text { dye }\end{array}$ & (year) & $\begin{array}{l}\text { Color- } \\
\text { less } \\
\text { organic } \\
\text { impuri- } \\
\text { ties } \\
(\%)^{*}\end{array}$ & $\begin{array}{c}\text { Subsi- } \\
\text { diary } \\
\text { dyes } \\
(\%)^{* *}\end{array}$ & $\begin{array}{l}\text { Total } \\
(\%)\end{array}$ & No. & $\begin{array}{c}\text { Food coal-tar } \\
\text { dye }\end{array}$ & (year) & $\begin{array}{l}\text { Color- } \\
\text { less } \\
\text { organic } \\
\text { impuri- } \\
\text { ties } \\
(\%) *\end{array}$ & $\begin{array}{l}\text { Subsi- } \\
\text { diary } \\
\text { dyes } \\
(\%)^{* *}\end{array}$ & $\begin{array}{c}\text { Total } \\
(\%)\end{array}$ \\
\hline $\begin{array}{r}1 \\
2 \\
3 \\
4 \\
5 \\
6 \\
7 \\
8 \\
9 \\
10 \\
11 \\
12 \\
13 \\
14 \\
15 \\
16\end{array}$ & Tartrazine & $\begin{array}{l}(1979) \\
(1980)\end{array}$ & $\begin{array}{l}0.10 \\
0.02 \\
0.01 \\
0.05 \\
0.02 \\
0.06 \\
0.07 \\
0.02 \\
0.02 \\
0.05 \\
0.17 \\
0.19 \\
0.18 \\
0.13 \\
0.14 \\
0.12\end{array}$ & $\begin{array}{l}0.06 \\
0.01 \\
0.07 \\
0.11 \\
0.17 \\
1.05 \\
1.04 \\
0.31 \\
0.03 \\
0.04 \\
0.21 \\
0.25 \\
0.53 \\
0.60 \\
0.68 \\
0.13\end{array}$ & $\begin{array}{l}0.16 \\
0.03 \\
0.08 \\
0.16 \\
0.19 \\
1.11 \\
1.11 \\
0.33 \\
0.05 \\
0.09 \\
0.38 \\
0.44 \\
0.71 \\
0.73 \\
0.82 \\
0.25\end{array}$ & $\begin{array}{l}55 \\
56 \\
57 \\
58 \\
59 \\
60 \\
61 \\
62 \\
63 \\
64 \\
65 \\
66 \\
67 \\
68 \\
69\end{array}$ & . & $\begin{array}{l}(1978) \\
(1979) \\
\\
(1980)\end{array}$ & $\begin{array}{l}0.12 \\
0.11 \\
0.12 \\
0.43 \\
0.50 \\
0.12 \\
0.11 \\
0.12 \\
0.43 \\
0.50 \\
0.37 \\
0.29 \\
0.26 \\
0.37 \\
0.28\end{array}$ & $\begin{array}{l}0.36 \\
0.63 \\
0.37 \\
0.30 \\
0.40 \\
0.36 \\
0.63 \\
0.37 \\
0.30 \\
0.40 \\
1.15 \\
1.07 \\
1.06 \\
1.24 \\
1.11\end{array}$ & $\begin{array}{l}0.48 \\
0.74 \\
0.49 \\
0.73 \\
0.90 \\
0.48 \\
0.74 \\
0.49 \\
0.73 \\
0.90 \\
1.52 \\
1.36 \\
1.32 \\
1.61 \\
1.39\end{array}$ \\
\hline $\begin{array}{l}17 \\
18 \\
19 \\
20 \\
21\end{array}$ & & & $\begin{array}{l}0.12 \\
0.14 \\
0.29 \\
0.22 \\
0.27\end{array}$ & $\begin{array}{l}0.13 \\
0.14 \\
0.85 \\
0.80 \\
0.87\end{array}$ & $\begin{array}{l}0.25 \\
0.28 \\
1.14 \\
1.02 \\
1.14\end{array}$ & $\begin{array}{l}70 \\
71 \\
72 \\
73 \\
74\end{array}$ & $\begin{array}{l}\text { Fast Green } \\
\text { FCF }\end{array}$ & (1980) & $\begin{array}{l}0.03 \\
0.02 \\
0.05 \\
0.07\end{array}$ & $\begin{array}{l}0.49 \\
0.49 \\
0.45 \\
0.47\end{array}$ & $\begin{array}{l}0.52 \\
0.51 \\
0.50 \\
0.54\end{array}$ \\
\hline $\begin{array}{l}22 \\
23 \\
24 \\
25 \\
26 \\
27 \\
28 \\
29 \\
30 \\
31 \\
32 \\
33 \\
34 \\
35 \\
36 \\
37 \\
38 \\
39\end{array}$ & $\begin{array}{l}\text { Sunset Yellow } \\
\text { FCF }\end{array}$ & $\begin{array}{l}(1978) \\
(1979)\end{array}$ & $\begin{array}{l}0.95 \\
0.49 \\
0.31 \\
0.18 \\
0.32 \\
0.69 \\
0.32 \\
2.41 \\
0.62 \\
0.54 \\
0.13 \\
0.10 \\
0.81 \\
0.61 \\
0.53 \\
0.68 \\
0.71\end{array}$ & $\begin{array}{l}0.65 \\
1.80 \\
1.34 \\
1.60 \\
0.92 \\
0.94 \\
1.38 \\
2.12 \\
0.91 \\
0.87 \\
0.48 \\
0.63 \\
0.68 \\
0.74 \\
0.52 \\
0.67 \\
0.70\end{array}$ & $\begin{array}{l}1.60 \\
2.29 \\
1.65 \\
1.78 \\
1.24 \\
1.63 \\
1.70 \\
4.53 \\
1.53 \\
1.41 \\
0.61 \\
0.73 \\
1.49 \\
1.35 \\
1.05 \\
1.35 \\
1.41\end{array}$ & $\begin{array}{l}75 \\
\\
76 \\
77 \\
78 \\
79 \\
80 \\
81 \\
82 \\
83 \\
84 \\
85 \\
86 \\
87 \\
88 \\
89 \\
90 \\
91\end{array}$ & $\begin{array}{l}\text { Brilliant Blue } \\
\text { FCF }\end{array}$ & $\begin{array}{l}(1978) \\
(1979)\end{array}$ & $\begin{array}{l}0.37 \\
0.47 \\
0.41 \\
0.34 \\
0.35 \\
0.37 \\
0.47 \\
0.73 \\
0.71 \\
1.06 \\
0.87 \\
0.66 \\
1.07 \\
0.94 \\
1.16 \\
1.84 \\
1.68\end{array}$ & $\begin{array}{l}0.67 \\
0.72 \\
0.50 \\
0.54 \\
0.49 \\
0.51 \\
0.31 \\
0.88 \\
1.04 \\
2.14 \\
1.44 \\
1.23 \\
0.88 \\
0.82 \\
0.76 \\
2.11 \\
1.24\end{array}$ & $\begin{array}{l}1.04 \\
1.19 \\
0.91 \\
0.88 \\
0.84 \\
0.88 \\
0.78 \\
1.61 \\
1.75 \\
3.20 \\
2.31 \\
1.89 \\
1.95 \\
1.82 \\
1.92 \\
3.95 \\
2.92\end{array}$ \\
\hline $\begin{array}{l}40 \\
41 \\
42 \\
43 \\
44 \\
45 \\
46 \\
47 \\
48 \\
49 \\
50 \\
51 \\
52 \\
53 \\
54\end{array}$ & Amaranth & $\begin{array}{l}(1978) \\
(1979) \\
(1980)\end{array}$ & $\begin{array}{l}0.27 \\
0.22 \\
0.23 \\
0.25 \\
0.28 \\
0.22 \\
0.21 \\
0.37 \\
0.37 \\
0.35 \\
0.37 \\
0.33 \\
0.26 \\
0.27 \\
0.26\end{array}$ & $\begin{array}{l}\text { ND } \\
\text { ND } \\
\text { ND } \\
\text { ND } \\
\text { ND } \\
\text { ND } \\
\text { ND } \\
\text { ND } \\
\text { ND } \\
\text { ND } \\
0.76 \\
1.09 \\
1.10 \\
0.65 \\
1.00\end{array}$ & $\begin{array}{l}0.27 \\
0.22 \\
0.23 \\
0.25 \\
0.28 \\
0.22 \\
0.21 \\
0.37 \\
0.37 \\
0.35 \\
1.13 \\
1.42 \\
1.36 \\
0.92 \\
1.26\end{array}$ & $\begin{array}{r}92 \\
\\
93 \\
94 \\
95 \\
96 \\
97 \\
98 \\
99 \\
100 \\
101 \\
102 \\
103 \\
104 \\
105\end{array}$ & $\begin{array}{l}\text { Indigo } \\
\text { Carmine }\end{array}$ & (1979) & $\begin{array}{l}0.38 \\
0.14 \\
0.06 \\
0.13 \\
0.15 \\
0.14 \\
0.62 \\
0.48 \\
0.91 \\
0.82 \\
0.98 \\
0.03 \\
0.02 \\
0.02\end{array}$ & $\begin{array}{l}0.97 \\
1.80 \\
1.35 \\
0.65 \\
2.71 \\
4.00 \\
5.18 \\
4.64 \\
5.73 \\
6.37 \\
0.43 \\
0.36 \\
0.48\end{array}$ & $\begin{array}{l}3.52 \\
1.11 \\
1.86 \\
1.48 \\
0.80 \\
2.85 \\
4.62 \\
5.66 \\
5.55 \\
6.55 \\
7.35 \\
0.46 \\
0.38 \\
0.50\end{array}$ \\
\hline
\end{tabular}

* Intermediate and residual starting material: expressed as sulfanilic acid

** Subsidiary dye: expressed as content of main dye

ND: less than $0.01 \%$ 
3. Survey of organic impurities in commercial food colors

Since few impurities were found in the reference standards, elution tests were carried out on commercial dyes. Typical chromatograms of seven dyes are shown in Fig. 1a, $1 \mathrm{~b}, 1 \mathrm{c}$ and $1 \mathrm{~d}$.

As shown in Fig. 1a-A, whole organic impurties in Tartrazine were detected at the UV wavelength of $254 \mathrm{~nm}$ on HPLC, while only subsidiary colors $A, B$ and $C$ were detected in the same sample at the visible wavelength of $428 \mathrm{~nm}$ as shown in Fig. 1a-B. Under these conditions, the peak area of $B$ (not the main color) was defined as subsidiary color, and the peak area of $A-B$ as colorless organic impurities. Main organic impurities identified were determined and the results are given in Table 2.

Organic impurities were added at the level of $0.1 \%$ to the test solutions and recovery tests were carried out. The recoveries of these compounds were more than $98.0 \%$ and the coefficients of variation were within \pm $3.0 \%$.

\section{Total amount of organic impurities}

In order to introduce HPLC into the purity tests of JSFA, it seemed desirable to define organic impurities in total rather than to determine individual compounds because it is very difficult to identify and determine individual compounds. Accordingly, the sums of residual starting materials plus reaction intermediates and subsidiary dyes were expressed as quantity of sulfanilic acid and main dye, respectively, because sulfanilic acid is a typical starting material, and the chemical structures of subsidiary dyes seem to be similar to those of the main dyes.

$\mathrm{E}_{1 \mathrm{~m}}^{1 \%} 254 \mathrm{~nm}$ values of common starting materials were as follows; sulfanilic acid (252), naphthionic acid (166), R acid (135), G acid (150), Schäffer acid (142), $o$-benzaldehydesulfonic acid (267), isatin-5-sulfonic acid (344). The results in Table 2 indicate that levels of or- ganic impurities can be expressed in terms of sulfanilic acid with sufficient accuracy for the present purpose. The analytical results for organic impurities in food coal-tar dyes are listed in Table 3.

Relatively large amounts of organic impurities (more than $3 \%$ in total) were obtained from No. 30 (Sunset Yellow FCF), Nos. 84 and 90 (Brilliant Blue FCF), and Nos. 92 and 98-102 (Indigo Carmine), while less than $1 \%$ impurities was found from Fast Green FCF samples.

Comparing the results for subsidiary color of Indigo Carmine obtained by the official paper chromatography procedure and the proposed HPLC method, no spot of subsidiary color was detected by paper chromatography, though many samples contained more than $3 \%$ of subsidiary color as determined by HPLC. Further, not only subsidiary color but also colorless organic impurities could be sufficiently separated and determined by HPLC.

Thus, the present HPLC method seems to be effective, and superior to the existing standard method.

\section{References}

1) Ministry of Health and Welfare: “The Japanese Standards of Food Additives, 4th ed." p. 494 497 (1978).

2) Link, W. B.: J. Assoc. Offic. Anal. Chem. 44, 43 53 (1961).

3) Davidek, J.: Z. Lebensm. Unters. Forsch. 132, 285 295 (1967).

4) Manjeet, S.: J. Assoc. Offic: Anal. Chem. 57, 358 359 (1974).

5) Manjeet, S.: ibid. 58, $48 \sim 49$ (1975).

6) Bailey C. J., Cox E. A., Springer J. A.: ibid. 61, $1404 \sim 1414$ (1978).

7) Noda, A., Nishiki, S.: J. Food Hyg. Soc. Japan 18, $321 \sim 327$ (1977).

8) Boley, N. P., Bunton, N. G., Crosby, N. T., Johnson, A. E., Roper, P., Somers, L.: Analyst 105, $589 \sim 599$ (1980). 